\title{
Preservation of macroparasite species via classic plastination: an evaluation
}

\author{
Moisés Gonzálvez ${ }^{1 *}$, Juana Ortiz ${ }^{1}$, María Navarro ${ }^{1}$, Rafael Latorre $^{2}$ \\ ${ }^{1}$ Department of Animal Health, Faculty of Veterinary Science, Regional Campus of International Excellence 'Campus Mare Nostrum \\ , University of Murcia, Murcia, Spain; \\ ${ }^{2}$ Department of Anatomy and Comparative Pathological Anatomy, Faculty of Veterinary Science, Regional Campus of International \\ Excellence 'Campus Mare Nostrum', University of Murcia, Murcia, Spain
}

\begin{abstract}
Plastination is a preservation method for biological specimens, with important advantages over classic conservation techniques with formaldehyde or alcohol. Plastinated specimens are dry, odourless, and free of carcinogenic and toxic solutions. There are only few references about the plastination of parasites. Moreover, there is no information on the effect of plastination on the morphology and morphometry of these animals. The aim of this study was to define a plastination protocol to preserve various species of parasites, namely the nematodes Parascaris equorum (Goeze, 1782); Ascaris suum Goeze, 1782 and Dirofilaria immitis (Leidy, 1856); the acanthecephalan Macracanthorhynchus hirudinaceus (Pallas, 1781); the trematodes Fasciola hepatica Linnaeus, 1758 and Dicrocoelium dendriticum (Rudolphi, 1819) and the tapeworm Taenia sp. in the best morphological and morphometric conditions. Results showed that some individuals suffered collapse (P. equorum, A. suum, and D. dendriticum). However, other parasites presented good results with almost no change after plastination (D. immitis, $M$. hirudinaceus and $F$. hepatica). In conclusion, conventional plastination allowed anatomical preservation of all helminths tested, but modifications to the protocol are needed to prevent collapse.
\end{abstract}

Keywords: parasites, silicone preservation, S10 technique, collections, teaching.

Today, most parasites used as teaching tools at secondary schools (biology, zoology), universities (anatomy, pathological anatomy), research centres and other institutions are commonly preserved with formaldehyde solution (formalin) and/or alcohol. These chemicals have significant disadvantages such as toxicity, cause shrinkage and colour changes of specimens, carcinogenicity, odour, specimens are wet, fluid levels require maintenance, necessity of wearing gloves to manipulate them, storage capacity, limited duration, etc. (McLaughlin 1994, Swenberg et al. 2013). The routine process of fixing anatomical specimens is risky and the compounds used may pose a significant health hazard.

Plastination is an innovative procedure that has revolutionised the way in which anatomical samples can be presented to students in human and veterinary anatomy (von Hagens et al. 1987). Plastination is an important alternative to preserve any type of biological material. It consists of replacement of corporal fluids and adipose tissue by a curable polymer under specific conditions.

There are very few papers on the use of plastination in parasitology (Asadi and Mahmodzadeh 2004, Kocevski et al. 2010, Essa et al. 2014, Kumar et al. 2017). Moreover, these studies do not present information about changes that are necessary in each phase of the plastination protocol. Therefore, it is difficult to validate the potential of plastinated parasites as a teaching-learning tool. Moreover, potential morphometric changes should be evaluated to validate this preservation alternative for parasites. It is clear that each parasite taxon needs a specific plastination protocol to prevent morphologic alterations and to conserve its particular anatomy (Gonzálvez et al. 2017).

Objectives for this study were as follows:

(i.) to adapt the S10 protocol for silicone plastination of six different groups of helminth parasites;

(ii.) to evaluate morphological and morphometric effects of the plastination procedure on these parasites.

\section{MATERIALS AND METHODS}

\section{Specimens}

Parasites used in this study were: the nematodes Parascaris equorum (Goeze, 1782) (10 specimens), Ascaris suum Goeze, $1782(\mathrm{n}=5)$ and Dirofilaria immitis (Leidy, 1856) ( $\mathrm{n}=5)$, the acanthocephalan Macracanthorhynchus hirudinaceus (Pallas, 1781) ( $\mathrm{n}=5)$, the trematodes Fasciola hepatica Linnaeus, 1758 $(\mathrm{n}=5)$ and Dicrocoelium dendriticum (Rudolphi, 1819) $(\mathrm{n}=10)$ and the cestode Taenia sp. $(\mathrm{n}=5)$ from the collection of the An- 
Table 1. Time variations in the plastination protocol (in minutes).

\begin{tabular}{lccc}
\hline Parasite /Assay & Dehydration & Impregnation & Curing \\
\hline Parascaris equorum (Goeze, 1782) & 4 & 4 & 5 \\
Ascaris suum Goeze, 1782 & 4 & 10 & 3 \\
Dirofilaria immitis (Leidy, 1856) & 4 & 5 & 5 \\
Macracanthorhynchus hirudinaceus (Pallas, 1781) & 2 & 5 & 4 \\
Fasciola hepatica Linnaeus, 1758 & 4 & 5 & 4 \\
Dicrocoelium dendriticum (Rudolphi, 1819) & 2 & 4 & 4 \\
Taenia sp. & 5 & 8 & 8 \\
\hline
\end{tabular}
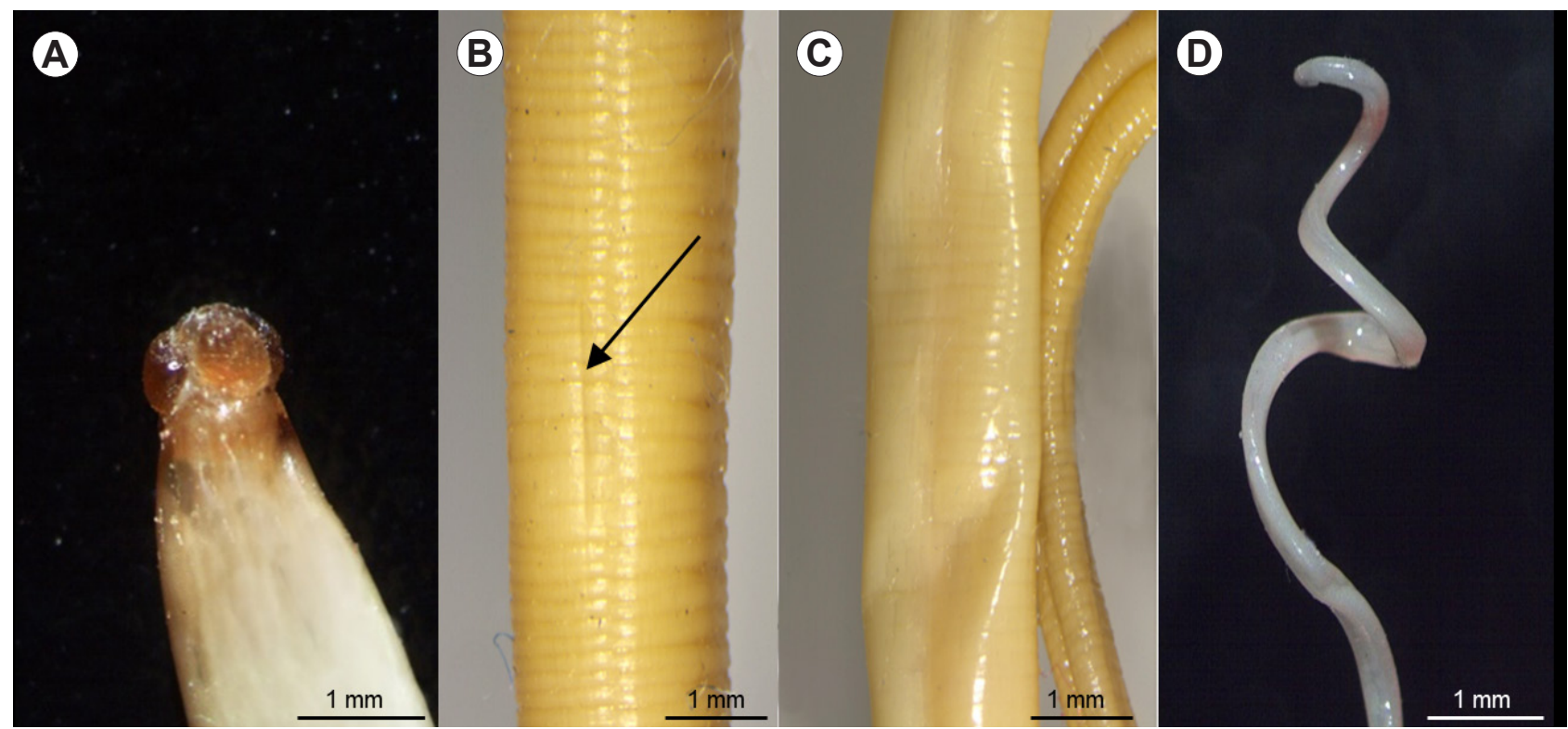

Fig. 1. Plastinated nematode specimens. A - plastinated Parascaris equorum (Goeze, 1782) (three lips in buccal region); B, C - plastinated Ascaris suum Goeze, 1782, transverse striations (B), and partially collapsed specimens (C); D - posterior region of a Dirofilaria immitis male; black arrow - cut area.

imal Health Department, University of Murcia, Spain. All specimens were fixed in formaldehyde and were inspected for structural alterations. Altered specimens were discarded.

\section{Plastination protocol}

The standard method of silicone plastination (Biodur ${ }^{\circledR}$ S10) was used (DeJong and Henry 2007). After specimen selection and fixation, dehydration of specimens was the first step in plastination. Parasites were placed in cold $\left(-25^{\circ} \mathrm{C}\right)$ acetone baths (freeze substitution). Three changes of cold acetone were used. The second step was the impregnation of the specimens with a silicone mixture $(\mathrm{S} 10+\mathrm{S} 3)$ by decreasing pressure (increasing vacuum). During impregnation, acetone in the tissue is vapourised from the cells and replaced by the silicone mixture. Finally, the silicone in the tissue was cured (polymerised) using the hardener S6.

To avoid the cuticle or tegument acting as a nearly impervious barrier during acetone replacement, a longitudinal incision of approximately one or two centimetres was made in the ventral side of about a half of specimens of P. equorum $(\mathrm{n}=5)$, A. suum $(\mathrm{n}=$ $2)$ and $M$. hirudinaceus $(\mathrm{n}=2)$. Because of their small size or for other technical reasons, D. immitis, F. hepatica, D. dendriticum and Taenia sp. were not incised. The quantity of acetone used in each bath was sufficient to cover all samples (200-300 ml) and acetone purity was measured with a precision acetonometer. During dehydration, the purity of the acetone after the last acetone bath was always higher than the $99.8 \%$ necessary to obtain the best results during impregnation.

Forced impregnation was carried out at $-25^{\circ} \mathrm{C}$, using silicone S10 and catalyst S3 $(100: 1)$ as the reaction-mixture in the vacuum chamber. After several days of forced impregnation (decreasing pressure) $5 \mathrm{~mm} \mathrm{Hg}$ was reached and impregnation was considered complete. Vacuum was released to normal atmosphere, the samples were removed from the impregnation chamber and drained of excess polymer at room temperature for 24 hours.

Curing was performed at room temperature using the vapour of cross-linker S6. During this phase, excess silicone was removed from the parasite's surface by wiping with paper towelling. When this was not possible, such as in the night or public holidays, specimens were stored at $-20^{\circ} \mathrm{C}$, which retards the curing reaction.

\section{Morphological and morphometric study}

Morphology of each specimen was evaluated; with special attention given to assessing the anatomy of each parasite. For morphometric evaluation, four parameters were measured to quantify changes during each phase of the plastination process:

1. Length (from anterior to posterior);

2. Maximum width (largest body width);

3. Minimum width (smallest body width);

4. Weight. 


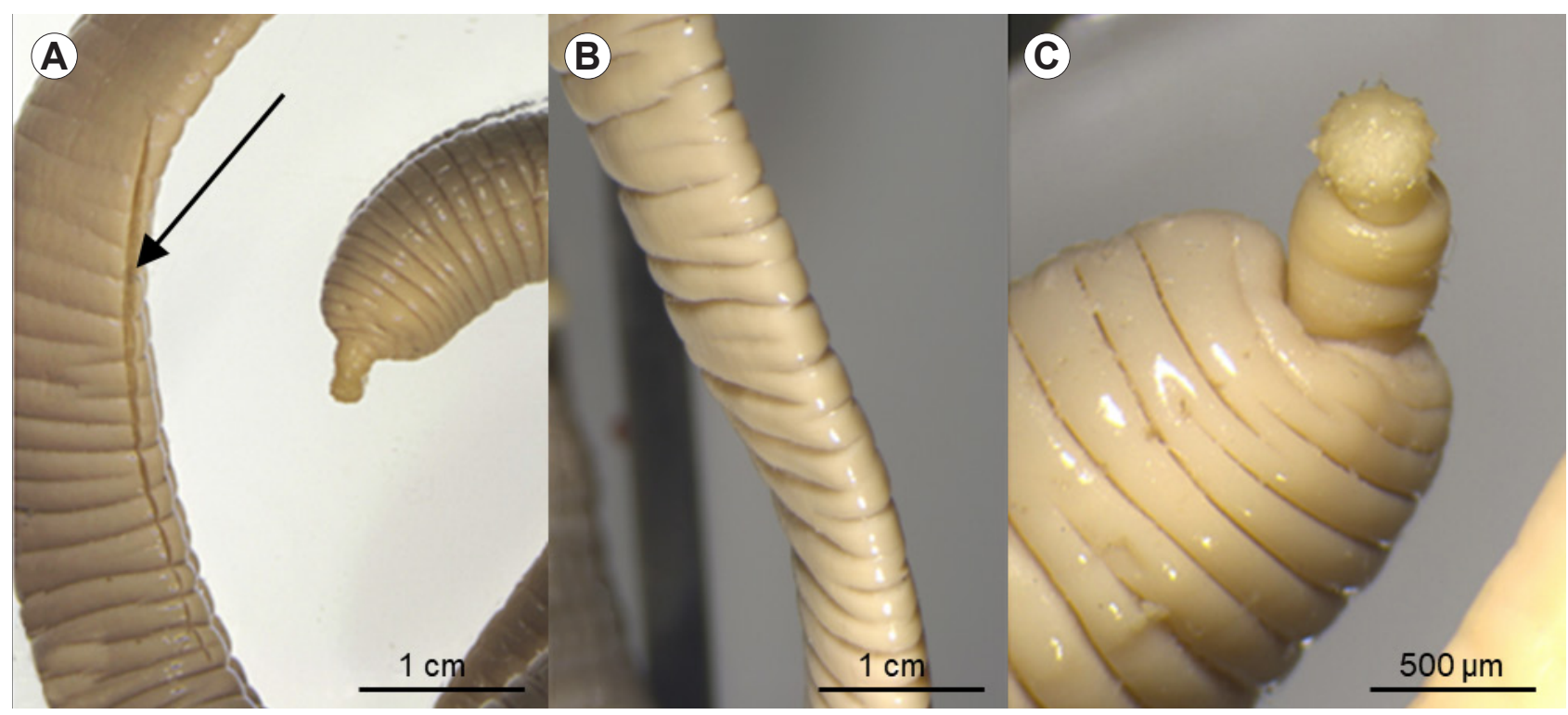

Fig. 2. Plastinated acanthocephalan Macracanthorhynchus hirudinaceus (Pallas, 1781). A - middle region; B - collapsed area; A, $\mathbf{C}$ - proboscis; black arrow - cut area.

Parameters were measured and recorded, if possible, after each step of the protocol: fixation, dehydration, impregnation and curing. For morphological and morphometric evaluation, a photomicroscope (Leica EZ Camera 2.4.1) with specific morphometry software (LAS EZ 2.1.0) was used.

Morphometric parameters were analysed for statistical differences using the non-parametric Wilcoxon test $(p<0.05)$ with $R$ studio software v1.0.143 (http://cran.r-project.org/).

\section{RESULTS}

\section{Plastination protocol}

Dehydration time of specimens varied from two days (Macracanthorhynchus hirudinaceus and Dicrocoelium dendriticum) to five days (Taenia sp.) (Table 1).

Impregnation was carried out without problems in all parasites. Specimens of Ascaris suum and Taenia sp. needed more time (eight to ten days) to reach the final pressure of $5 \mathrm{~mm} \mathrm{Hg}$ or lower than the remaining species (Table 1). When the cessation of acetone bubbling occurred around 5 $\mathrm{mm} \mathrm{Hg}$, the specimens were considered impregnated. At that stage only a few larger bubbles appeared on the polymer surface.

Time to complete curing of Taenia sp. was almost double (eight days) (Table 1) compared with other plastinated parasites.

\section{Morphology and morphometry}

Nematodes, acanthocephalans and small trematodes often collapsed, altering their morphology and morphometry at the macroscopic level. No morphological or morphometric differences were observed between those specimens which had been cut and those which had not been cut. Therefore, no relationship was found concerning level of collapse between specimens with or without cut in the cuticle (Table 2).
Values for each morphometric parameter evaluated in each step of the protocol and for each parasite are presented in Table 2. Some data for Fasciola hepatica and D. dendriticum could not be obtained because the time required for measurement exceeded the maximum time permitted to prevent acetone evaporation from specimens. In contrast, the excessive winding of specimens of Taenia sp. allowed measurement only at the beginning and at the end of the plastination process to prevent rupture during handling. A detailed description of morphological and morphometric results by parasite specimen is presented below (see also Table 2).

Parascaris equorum (Fig. 1A): The three lips located at the anterior region are important structures of this species. The lips were preserved well and accurately after plastination. However, all specimens suffered collapse along their length during impregnation and the collapse remained after curing. Weight was the only parameter that decreased significantly $(-57 \%$; p-value $<0.05)$ after dehydration (Table 2).

Ascaris summ (Fig. 1B, C): The appearance of individual plastinated specimens was similar to that before plastination. Microscopic characteristics of lips, cuticle and transverse striations were well preserved (Fig. 1B). However, some specimens collapsed during impregnation (Fig. 1C). Width decreased significantly $(-90 \%)$ during plastination mainly during the impregnation step (Table 2).

Dirofilaria immitis (Fig. 1D): All specimens were males, characterised by having the tail end coiled. This delicate, thin structure was perfectly conserved by plastination. The results after plastination showed no evident morphological modifications, although fragility of these nematodes was noted during the dehydration phase when specimens became very rigid. The weight increased significantly (200\%) after the impregnation phase (Table 2).

Macracanthorhynchus hirudinaceus (Fig. 2A-C): The proboscis with its hooks (Fig. 2A, C) was preserved in all 
Table 2. Recorded length, width (both in millimetres) and weight (in grams) of specimens at plastination intervals, mean data \pm standard deviation, $(*)$ significant values $(\mathrm{p}<0.05)$.

\begin{tabular}{|c|c|c|c|c|c|c|}
\hline Parasite & Measures & Initial & Dehydration & Impregnation & Curing & $\begin{array}{c}\text { Total retraction } \\
\text { change }\end{array}$ \\
\hline \multirow{4}{*}{$\begin{array}{l}\text { Parascaris equorum } \\
\text { (Goeze, 1782) }\end{array}$} & length & $17 \pm 2$ & $16 \pm 1.7$ & $15 \pm 1.6$ & $17 \pm 3$ & $+1.4 \%$ \\
\hline & max. width & $0.5 \pm 0.04$ & $0.4 \pm 0.04$ & $0.4 \pm 0.03$ & $0.5 \pm 0.03$ & $-0.13 \%$ \\
\hline & min. width & $0.4 \pm 0.1$ & $0.4 \pm 0.1$ & $0.4 \pm 0.1$ & $0.4 \pm 0.1$ & $-0.14 \%$ \\
\hline & weight & $1.6 \pm 0.4^{*}$ & $0.7 \pm 0.2$ & $0.6 \pm 0.2$ & $0.7 \pm 0.1$ & $-55 \%$ \\
\hline \multirow{4}{*}{$\begin{array}{l}\text { Ascaris suum } \\
\text { Goeze, } 1782\end{array}$} & length & $191 \pm 44$ & $179 \pm 44$ & $179 \pm 44$ & $168 \pm 43$ & $-12 \%$ \\
\hline & max. width & $4 \pm 0.8$ & $3.9 \pm 1.9$ & $0.4 \pm 0.1 *$ & $0.4 \pm 0.1$ & $-91 \%$ \\
\hline & min. width & $0.5 \pm 0.2$ & $0.5 \pm 0.2$ & $0.5 \pm 0.1$ & $0.6 \pm 0.1$ & $+14 \%$ \\
\hline & weight & $1.4 \pm 0.8$ & $1 \pm 0.7$ & $1 \pm 0.7$ & $1.0 \pm 0.7$ & $-27 \%$ \\
\hline \multirow{4}{*}{$\begin{array}{l}\text { Dirofilaria immitis } \\
\text { (Leidy, 1856) }\end{array}$} & length & $142 \pm 16$ & $122 \pm 31$ & $126 \pm 15$ & $125 \pm 16$ & $-12 \%$ \\
\hline & max. width & $0.9 \pm 0.1$ & $0.6 \pm 0.07$ & $0.6 \pm 0.1$ & $0.7 \pm 0.1$ & $-25 \%$ \\
\hline & min. width & $0.3 \pm 0.1$ & $0.2 \pm 0.05$ & $0.2 \pm 0.1$ & $0.1 \pm 0.04$ & $-48 \%$ \\
\hline & weight & $0.02 \pm 0.01$ & $0.02 \pm 0.02$ & $0.06 \pm 0.01 *$ & $0.06 \pm 0.003$ & $+200 \%$ \\
\hline \multirow{4}{*}{$\begin{array}{l}\text { Macracanthorhynchus } \\
\text { hirudinaceus } \\
\text { (Pallas, 1781) }\end{array}$} & length & $250 \pm 66$ & $247 \pm 63$ & $229 \pm 58$ & $235 \pm 60$ & $-6 \%$ \\
\hline & max. width & $1 \pm 2$ & $0.54 \pm 0.06$ & $0.6 \pm 0.1$ & $0.7 \pm 0.1$ & $-22 \%$ \\
\hline & min. width & $1 \pm 0.3$ & $1.15 \pm 0.15$ & $1.4 \pm 0.4$ & $1.4 \pm 0.4$ & $+18 \%$ \\
\hline & weight & $2.6 \pm 1.2$ & $2.1 \pm 1.1$ & $2.0 \pm 0.7$ & $2 \pm 1$ & $-24 \%$ \\
\hline \multirow{4}{*}{$\begin{array}{l}\text { Fasciola hepatica } \\
\text { Linnaeus, } 1758\end{array}$} & length & $16 \pm 2.2$ & \multirow{4}{*}{ No data } & $13 \pm 2.7$ & $15 \pm 2$ & $-9 \%$ \\
\hline & max. width & $8 \pm 2$ & & $7 \pm 0.6$ & $6 \pm 1$ & $-22 \%$ \\
\hline & min. width & $2 \pm 0.8$ & & $2 \pm 0.3$ & $2 \pm 0.6$ & $-11 \%$ \\
\hline & weight & $0.1 \pm 0.4$ & & $0.1 \pm 0.01$ & $0.08 \pm 0.02$ & $-8 \%$ \\
\hline \multirow{4}{*}{$\begin{array}{l}\text { Dicrocoelium dendriticum } \\
\text { (Rudolphi, 1819) }\end{array}$} & length & $8.5 \pm 2$ & \multirow{4}{*}{ No data } & $7 \pm 1^{*}$ & $5 \pm 0.9$ & $-31 \%$ \\
\hline & max. width & $2 \pm 0.3$ & & $1.7 \pm 0.2$ & $1.6 \pm 0.2$ & $-19 \%$ \\
\hline & min. width & $0.9 \pm 0.2$ & & $0.3 \pm 0.1 *$ & $0.3 \pm 0.1$ & $-68 \%$ \\
\hline & weight & $0.004 \pm 0.001$ & & $0.004 \pm 0.001$ & $0.004 \pm 0.0006$ & $-16 \%$ \\
\hline \multirow{4}{*}{ Taenia sp. } & length & $20 \pm 9$ & \multirow{4}{*}{ No data } & \multirow{4}{*}{ No data } & No data & No data \\
\hline & max. width & $5.5 \pm 0.6$ & & & $5 \pm 0.3$ & $-8 \%$ \\
\hline & min. width & $1.2 \pm 0.3$ & & & $0.8 \pm 0.2$ & $-19 \%$ \\
\hline & weight & $1.0 \pm 0.1$ & & & $0.9 \pm 0.03$ & $-15 \%$ \\
\hline
\end{tabular}
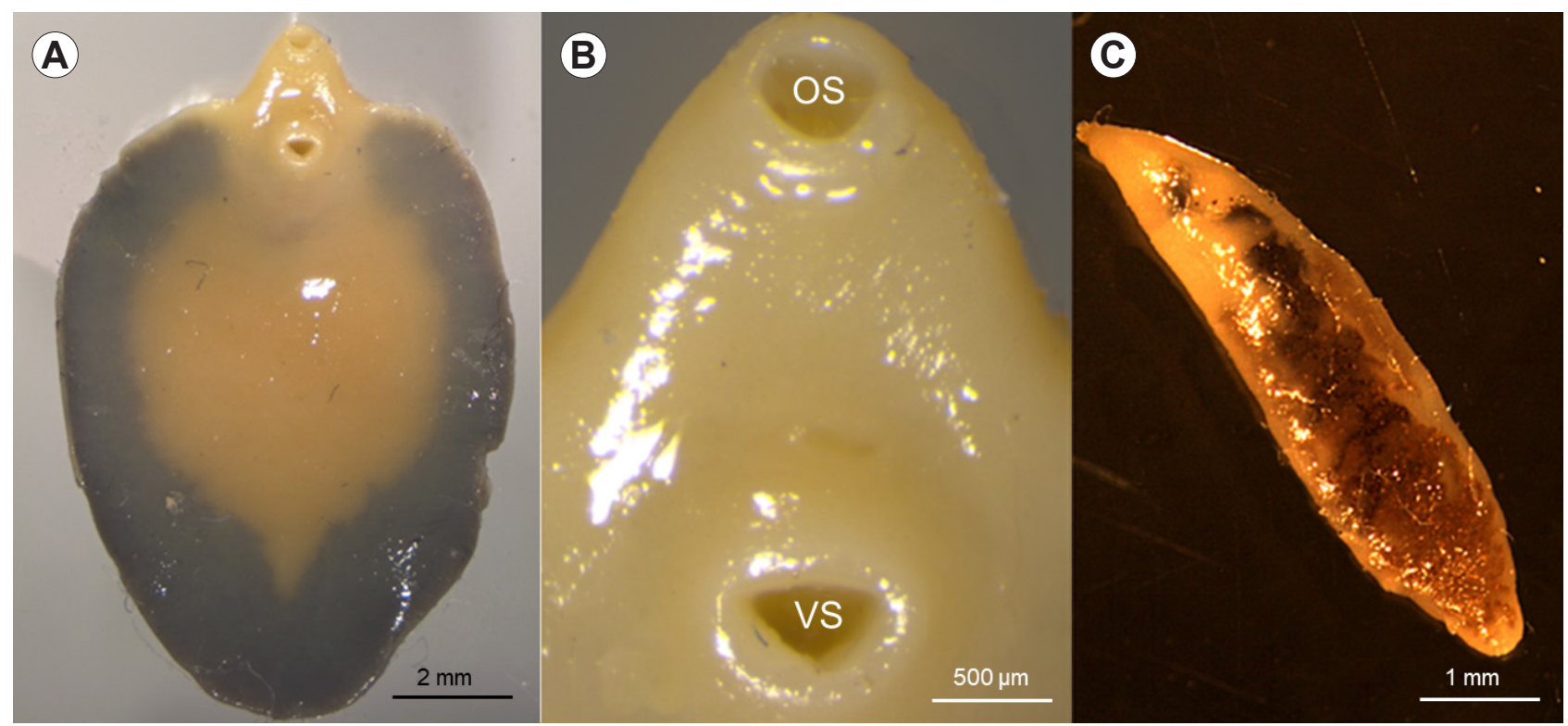

Fig. 3. Plastinated trematode specimens. A - plastinated Fasciola hepatica Linnaeus, 1758; B - oral (OS) and ventral (VS) suckers; C - plastinated Dicrocoelium dendriticum (Rudolphi, 1819), dorsal view with visualisation of internal structures.

specimens, as well as striations of the body (Fig. 2 A-C). All specimens were effectively plastinated except one that collapsed during impregnation. It is interesting to note the fragility of their structures caused by the acquired rigidity, although they were less fragile than $D$. immitis. No morphometric parameters showed statistically significant alterations (Table 2).
Fasciola hepatica (Fig. 3A,B): All specimens showed good results with plastination (Fig. 3A), when compared to parasites preserved in formaldehyde, alcohol or other traditional preservation methods. Oral and ventral (Fig. 3B2) suckers (Fig. 3B) maintained their relationship after plastination. Morphometric measurements were not significantly altered during plastination (Table 2). 


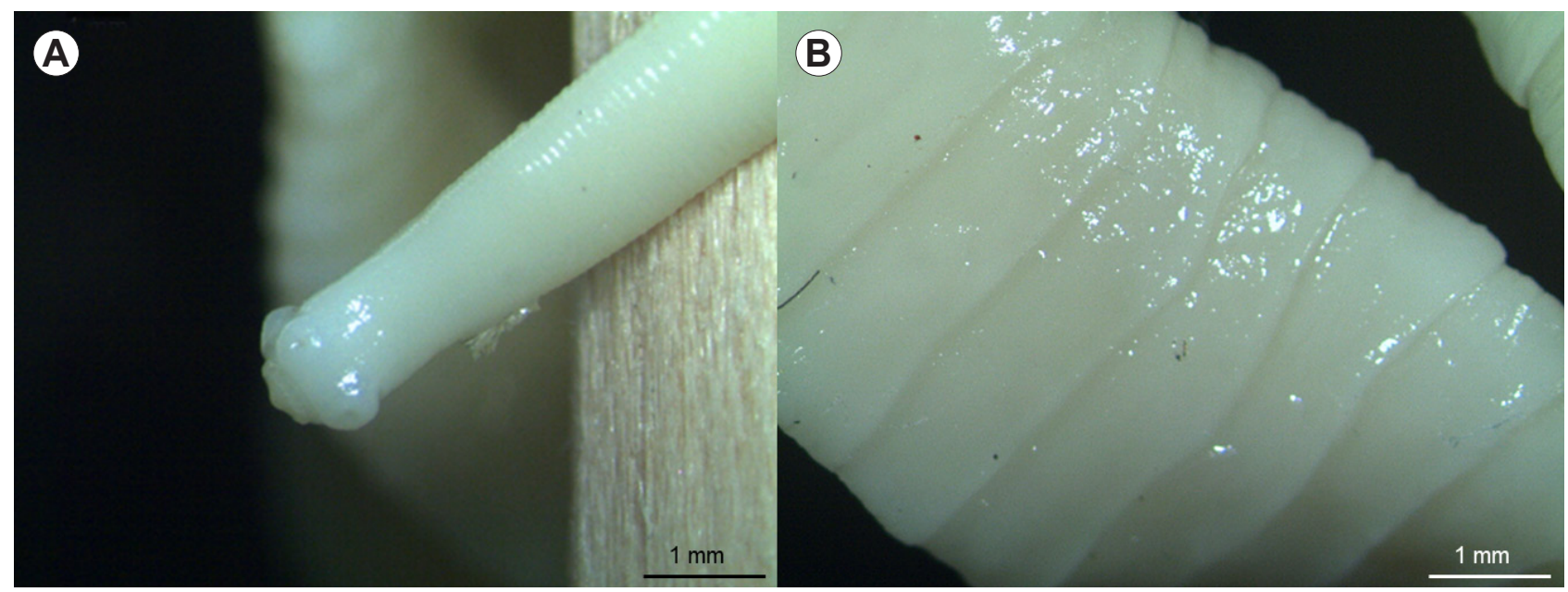

Fig. 4. Plastinated cestode Taenia sp. A - anterior end with suckers; $\mathbf{B}$ - central area with characteristic proglottids.

Dicrocoelium dendriticum (Fig. 3C): Good results were obtained in three specimens, without morphological alterations. Internal structures remained visible externally, just as they were before plastination. The remaining seven specimens wrinkled. These specimens were very small and difficult to manipulate. They had morphometric decreases in length $(-31 \%)$ and minimum width $(-68 \%)$ during impregnation (Table 2).

Taenia sp. (Fig. 4): All plastinated specimens maintained a similar appearance to the specimens before plastination. In particular, structures such as the scolex with suckers (Fig. 4A) and the central area of the strobili with characteristic proglottids (Fig. 4B) were well preserved. Morphometric values showed no differences for any parameter assessed (Table 2).

\section{DISCUSSION}

Results show that plastination can be used to preserve parasites that are commonly used as learning tools in veterinary parasitology. Results indicate that it is possible to plastinate these parasites and retain morphological and morphometric characteristics, similar to formalin-preserved specimens.

It is clear that the different types of parasites tested require different times for individual phases of the plastination protocol, based on size and morphology. This is similar to reports for other specimens which required protocol modifications to obtain the best morphological and morphometric results (Gonzálvez et al. 2017). These plastination protocol modifications have also been described in other areas such as embryology, herpetology and zoology when the cuticle, tegument or skin of a specimen acts as a barrier that can interfere with the exchange of acetone and polymer during dehydration and impregnation phases, respectively (Asadi 1998, Schaap 1998, Wendel et al. 2008, Tiwari et al. 2012, Ekim et al. 2017).

Specimens with a strong, thick surface layer (cuticle or tegument) have to be cut to avoid collapse of the whole specimen. However, this change in the protocol was unnecessary in parasites without a body cavity (Fasciola hepati$\mathrm{ca}$ ) or with a very thin cuticle (Dirofilaria immitis) (Cheng
1978). Another possible method to prevent collapse could be to prolong impregnation time and warm the impregnation mixture from $-25^{\circ} \mathrm{C}$ to $15^{\circ} \mathrm{C}$ at the end of the impregnation to reduce polymer viscosity (Weiglein 1996, Sora 2017).

It is important to use a standardised and universally accepted plastination protocol, which helps assure the ability to achieve repeatable results. The conventional S10 protocol (Biodur $\left.{ }^{\circledR}\right)$, the most common silicone technique, was used. Impregnation is the most critical step of silicone plastination protocol (Henry 1992, Henry and Nel 1993, Ottone et al. 2014). The final result of plastination depends on complete substitution of body fluid by a curable polymer. Slowly decreasing the atmospheric pressure to below $5 \mathrm{~mm} \mathrm{Hg}$ is necessary, contrary to results reported by $\mathrm{Ku}-$ mar et al. (2017), who performed the impregnation under atmospheric pressure.

The time for dehydration for Dicrocoelium dendriticum and Macracanthorhynchus hirudinaceus was shorter than in other parasites. This could be due to the small size of $D$. dendriticum and the small volume of tissue to be dehydrated (Beck et al. 2015). The tegument of M. hirudinaceus is a very thin structure (Cheng 1978) and this fact could explain faster dehydration compared to others parasites.

The longer impregnation time for Ascaris suum could be related to their great width and length and their thick cuticle (Cheng 1978). These factors are likely to increase the time necessary for escape of acetone and entrance of polymer-mix through the cuticle. A similar situation could be expected for Parascaris equorum, but they collapsed from the very beginning during impregnation. Increased impregnation time of specimens of Taenia sp., may be related to the large contact surface of this parasite, with many proglottids (Willms 2008). Increased weight of Dirofilaria imitis could be related to its small width because it was difficult to remove excessive polymer from the surface during curing.

Taenia sp. required a longer time to cure than other species, which could be related to the larger surface area and its shape that made it difficult to remove the excess silicone. Willms (2008) reports that Taenia sp. has the largest 
surface area compared with other tapeworms, such as $D i$ pylidium caninum.

Plastinated specimens exhibited a reduction in size compared with wet individuals before plastination, which was significant in A. suum, P. equorum and in D. dendriticum. In the remaining parasites, the changes were not significant.

Although plastination of these parasites is possible with the protocol used, there are some limitations. The most important is reduced flexibility of some specimens. Flexibility might be improved by two methods. First, by changes in the fixation protocol before plastination. The use of a very weak formalin solution (1-2\%) may produce more elastic specimens and therefore better results after plastination. Second, use of lower viscosity silicone, such as S15 (Biodur $\left.{ }^{\circledR}\right)$, which may allow easier impregnation of specimens. Also, the viscosity of the silicone impregnation bath may be decreased by using it at room temperature to obtain a better and faster impregnation. However, with the Biodur ${ }^{\circledR}$ method, room temperature speeds up the S3 action increasing the polymer-mix viscosity, and the mixture may no longer be valid for impregnation after a few weeks or months (Henry 1990, Zheng et al. 1998, Sagoo and Adds 2013). Another alternative for the regular cold S10 protocol would be to prolong the curing time but without crosslinker (S6), therefore with almost no exposure to S6 vapors. It would increase flexibility of specimens (Weiglein and Henry 1993).
It is also important to consider that some characteristics of parasites can complicate their management during and after plastination. Parasites with a low body weight such as $D$. dendriticum seem easier to handle in a wet environment, so plastination is not a good option for their conservation.

There are some papers supporting different types of plastinated specimens as excellent educational tools ( $\mathrm{Lu}$ et al. 2008, Raja and Sultana 2012, Prasad et al. 2015, Gonzálvez et al. 2017, Klaus et al. 2017). Other reports, mainly those focused on anatomy, have assessed plastinated specimens as teaching-learning tools by quantifying the improvement of student knowledge (Latorre et al. 2007, 2016, Riederer 2014).

The results presented in this work validate the silicone plastination technique as an alternative preservation technique for macroparasites that can be used as a teaching tool, avoiding the exposure to toxic chemicals such as formaldehyde solution. However, more studies are necessary to adjust the conventional protocol for individual parasite groups because individual anatomical characteristics influence the collapse of structures in some species.

Acknowledgements. We wish to express our appreciation to José Albarracín and Mariano Orenes (Department of Anatomy and Compared Pathological Anatomy, Veterinary School, University of Murcia) for technical assistance, as well as the staff of Parasitology and Parasitic Diseases (Department of Animal Health, Veterinary School, University of Murcia) for donating parasite specimens.

\section{REFERENCES}

AsADI M.H. 1998: Plastination of caviar fish with S10 technique in Iran. In: Proceedings of $9^{\text {th }}$ International Conference on Plastination, Trois-Rivières, Canada, 5-10 July 1998. J. Plast. 13: 37.

Asadi M.H., Mahmodzadeh A. 2004: Ascaris plastination through S10 techniques. J. Plast. 19: 20-21.

Beck M.A., Goater C.P., Colwell D.C. 2015: Comparative recruitment, morphology and reproduction of a generalist trematode, Dicrocoelium dendriticum, in three species of host. Parasitology 142: 1297-1305.

Cheng T.C. (Ed.) 1978: Parasitología General. AC, Spain, 965 pp.

DeJong K., Henry R.W. 2007: Silicone plastination of biological tissue: cold-temperature technique - BiodurTM S10/S15 technique and products. J. Plast. 22: 15-19.

Ekim O., Haziroglu R.M., Insal B., Bakici C., Akgün R.O., TunAli S. 2017: A modified S10B silicone plastination method for preparation and preservation of scaled reptile specimens. Ankara Univ. Vet. Fak. 64: 155-160.

Essa I., Azzal G., Al-Azizz S., Abdulkhalek Sawad A., SaMAR G.H. 2014: Plastination of arthropods using S10 technique. Basrah J. Vet. Res. 11: 18-25.

Gonzálvez M., Ortiz J., Latorre R. 2017: S10 Plastination technique for preservation of parasites: the case of Oestrus ovis larvae. J. Plast. 29: 5-10.

von Hagens G., Tiedemann K., Kriz W. 1987: The current potential of plastination. Anat. Embryol. 175: 411-421.

HENRY R.W. 1990: Room-temperature "forced air" impregnation of dried lungs with S10/S3-xylene mix. J. Plast. 4: 14-15.

Henry R.W. 1992: Plastination - forced impregnation. J. Plast. 6: 4-5.

Henry R.W., Nel P.P.C. 1993. Forced impregnation for the standard S10 method. J. Plast. 7: 27-31.
Klaus R., Royer D., Corral J., Stabio M.E. 2017: Use and perceptions of plastination among anatomy medical educators in the United States. FASEB J. 31: 733.4.

Kocevski Z., Stefanovska J., Ilieski V., Pendovski L., Atanaskova E. 2010: Improved determination of macroscopic parasite preparations using S10 modified plastination procedure. Mac. Vet. Rev. 2: 7-14.

Kumar N., Das B., Solanki J.B., Jadav M.M., Menaka R. 2017: Plastination of macroparasites: an eco-friendly method of long-term preservation. Vet. World. 10: 1394-1400.

Latorre R., Bainbridge D., Tavernor A., López Albors O. 2016: Plastination in anatomy learning: an experience at Cambridge University. J. Vet. Med. Educ. 43: 226-34.

Latorre R.M., García-Sanz M.P., Moreno M., Hernández F., Gil F., López O., Ayala M.D., Ramírez G., Vázquez J.M., Arencibia A., Henry R.W. 2007: How useful is plastination in learning anatomy? J. Vet. Med. Educ. 34: 172-176.

Lu Z., Li C.M., Qiao Y., Yan Y., Yang X. 2008: Effect of inhaled formaldehyde on learning and memory of mice. Indoor Air. 18: 77-83.

McLaughlin J.K. 1994: Formaldehyde and cancer: a critical review. Int. Arch. Occup. Environ. Hlth. 66: 295-301.

Ottone N., Cirigliano V., Lewicki M., Bianchi H., Aja-Guardiola A.G., Algieri R., Cantin M., Fuentes R. 2014: Plastination technique in laboratory rats: an alternative resource for teaching, surgical training and research development. Int. J. Morphol. 32: 1430-1435.

Prasad G., Bhavana K., Siddharth P., Dinzar K., Rahul G.T. 2015: Preservation of tissue by plastination: a review. Int. J. Adv. Hlth. Sci. 11: 27-31. 
Raja D.S., Sultana B. 2012: Potential health hazards for students exposed to formaldehyde in the gross anatomy laboratory. J. Environ. Hlth. 74: 36-40.

Riederer B.M. 2014: Plastination and its importance in teaching anatomy. Critical points for long-term preservation of human tissue. J. Anat. 224: 309-315.

SAgoo M.G., AdDs P.J. 2013: Low-temperature dehydration and room-temperature impregnation of brain slices using BiodurTMS10/S3. J. Plast. 25: 3-8.

SchaAp C.J. 1998: Plastination of fish and lobsters. J. Plast. 13: 38

Sora M.C. 2017: Room temperature impregnation with cold temperature Biodur ${ }^{\circledR}$ Silicone: a study of viscosity. J. Plast. 29: 26-29.

Swenberg J.A., Moeller B.C., Lu K., Rager J.E., Fry R., STARR T.B. 2013: Formaldehyde carcinogenicity research: 30 years and counting for mode of action, epidemiology, and cancer risk assessment. Toxicol. Pathol. 41: 181-189.

Tiwari S., Nandlal B., Shama Sundar N.M. 2012: Plastinated fetus: 3D CT scan (VRT) evaluation. Indian. J. Dent. Res. 23: $686-688$.

Weiglein A.H. 1996: Plastination - a teaching and research tool. J. Plast. 11: 34.

Weiglein A.H., Henry R.W. 1993: Curing (hardening, polymerization) of the polymer - Biodur S10. J. Plast. 7: 32-35.

Wendel H., Stark R., Plendl J. 2008: Plastination of reptiles for veterinary education. J. Plast. 23: 62-63.

WiLLms K. 2008: Morphology and biochemistry of the pork tapeworm, Taenia solium. Curr. Top. Med. Chem. 5: 375-382.

Zheng T.Z., LiU J., Zhu K. 1998: Plastination at room temperature. J. Plast. 13: 21-25.

Cite this article as: Gonzálvez M., Ortiz J., Navarro M., Rafael L. 2018: Preservation of macroparasite species via classic plastination: An evaluation. Folia Parasitol. 65: 019. 